\title{
Mineração
}

\section{Espessadores no beneficiamento de minério de ferro}

\section{Thickeners in iron ore processing}

\section{Nilton Carlos Torquato \\ Especialista em Processo Mineral da Vale \\ nilton.torquato@vale.com}

José Aurélio Medeiros da Luz

Engenheiro de Minas - Professor Adjunto do DEMIN/EM/UFOP

jaurelio@demin.ufop.br

\section{Resumo}

Esse trabalho visa a comparar estudos de espessamento realizados em escala industrial com ensaios de sedimentação realizados em escala de bancada e propõe a utilização de fatores de correção nos métodos clássicos de dimensionamento de espessadores convencionais. A prática industrial, no âmbito do tratamento de minérios de ferro no Brasil, tem consolidado uma modificação substancial no método clássico de Kynch (com traçado de Talmage \& Fitch), a qual consiste em adotar, para o traçado, a concentração mássica de sólidos na proveta após 24 horas, no lugar da concentração nominal do underflow no espessador industrial. Os ensaios indicam que a área unitária assim obtida ainda deve ser afetada com os fatores de correção. Esse fator, multiplicativo, é de 0,64, para espessadores de lamas, e de 1,3, para espessadores de concentrado fino (pellet feed).

Palavras-chave: Espessador, dimensionamento, sedimentação.

\begin{abstract}
This article displays a thickness comparison between an industrial scale campaign test and some bench scale tests for sedimentation and proposes correction factors for the classical dimensioning methods for the conventional thickeners. Brazilian iron ore processing has consolidated a substancial modification of the classical Kynch's method (under the Talmage \& Fitch's graphical procedure). It involves the adoption of the mass concentration value corresponding to the height of the slurry/ supernatant interface after 24 hours of rest in a conventional graduated cylinder test, instead of that corresponding to the nominal underflow concentration in the industrial thickener. The tests indicate that the calculations for the solid-loading area need to be corrected by a multiplicative factor of 0.64 for slime thickeners and 1.3 for pellet feed thickeners.
\end{abstract}

Keywords: Thickening, sizing, settling.

\section{Introdução}

A vasta utilização dos espessadores promove crescente interesse em se entenderem a operação e o dimensionamento desses equipamentos, com a finalidade de melhorar seu desempenho no atendimento às suas diferentes características operacionais. Exemplo de tentativa de metodologia alternativa de previsão do processo de sedimentação pode ser visto em Luz (2009). O espessador recebe alimentação em forma de polpa e - sob a influência da gravidade - gera dois produtos; um transbordado, dito overflow, normalmente água clarificada, e um espessado, dito underflow, produto com maior concentração de sólidos.

O presente trabalho está adstrito ao âmbito do beneficiamento de minérios de ferro e teve como objetivo precípuo obter correlação entre resultados de ensaios em proveta e de operações industriais.

Para as condições reinantes em espessamento, a concentração volumétrica 
de partículas é grande, o que faz com que haja regime de sedimentação por zona, com a mútua interferência das partículas na sedimentação. Assim, as equações para sedimentação discreta perdem sua

Onde:

$\mathrm{z}_{0}(\mathrm{t})$ - cota da interface clarificada no instante $t[\mathrm{~m}]$.

$z_{\infty}(t)$ - cota de equilíbrio da interface clarificada $(\mathrm{t}=\infty)[\mathrm{m}]$.

Já $a$ e $b$ são os parâmetros do modelo, e dependem das características das partículas e do ambiente físico-químico e químico da polpa. O parâmetro a é adimensional, enquanto $b$ tem dimensão de validade.

Isso pode ser apreciado nos ensaios de sedimentação em provetas para dimensionamento de espessadores. O tratamento de nuvem experimental de pontos de

$z(t)=\left(z_{0}-z_{\infty}\right) \times\left(1-\frac{t^{a}}{t^{a}+b^{a}}\right)+z_{\infty}$

tempo e representa o intervalo temporal até que a interface atinja a cota em que tenha alcançado $50 \%$ de seu percurso evolutivo (similar ao conceito de meiavida, na física e química).

A equação anteriormente apresentada foi validada com inúmeros ensaios com muitos materiais, como finos de manganês, hidróxido de alumínio, lamas argilosas de hidrociclones de usinas de

$$
v(t)=\frac{d z(t)}{d t}=z^{\prime}(t)=-\left(z_{0}-z_{\infty}\right) \times\left[\frac{a \times b^{a} \times t^{a-1}}{\left(t^{a}+b^{a}\right)^{2}}\right]
$$

numerosos ensaios, feito por Luz (2009), permitiu o estabelecimento da seguinte equação descritora da evolução da cota (z) da interface entre o líquido clarificado e a polpa turva, em provetas:

beneficiamento densitário de minerais pesados e finos de minério de ferro (Luz, 2009; Luz, 2009b).

Como se vê, a equação de evolução da cota da interface é uma modificação da equação sigmoidal de Hill. A velocidade de sedimentação em zona (em ensaios de proveta) é obtida pela sua derivada em relação ao tempo de repouso, resultando a expressão a seguir:

Percebe-se que há frenagem devida ao aumento da concentração de sólidos nos horizontes inferiores, a qual pode ser de sedimentação é porque se trata de descensão da interface com o tempo.

$$
a(t)=z^{\prime \prime}(t)=-\frac{\left(z_{0}-z_{\infty}\right) \times a \times b^{a} \times t^{a-2} \times\left[(a-1) \times b^{a}-(a+1) \times t^{a}\right]}{\left(t^{a}+b^{a}\right)^{3}}
$$

O dimensionamento do espessador consiste, basicamente, no cálculo da área unitária. Normalmente é realizado com base em ensaios de sedimentação em escala de bancada, utilizando-se provetas graduadas de $1.000 \mathrm{ml}$ ou $2.000 \mathrm{ml}$.
Seu dimensionamento também pode ser realizado em escala-piloto. No entanto, é difícil, nesse caso, regularizar o regime operacional para se garantir a constância da vazão, da concentração mássica de sólidos e de sua granulação

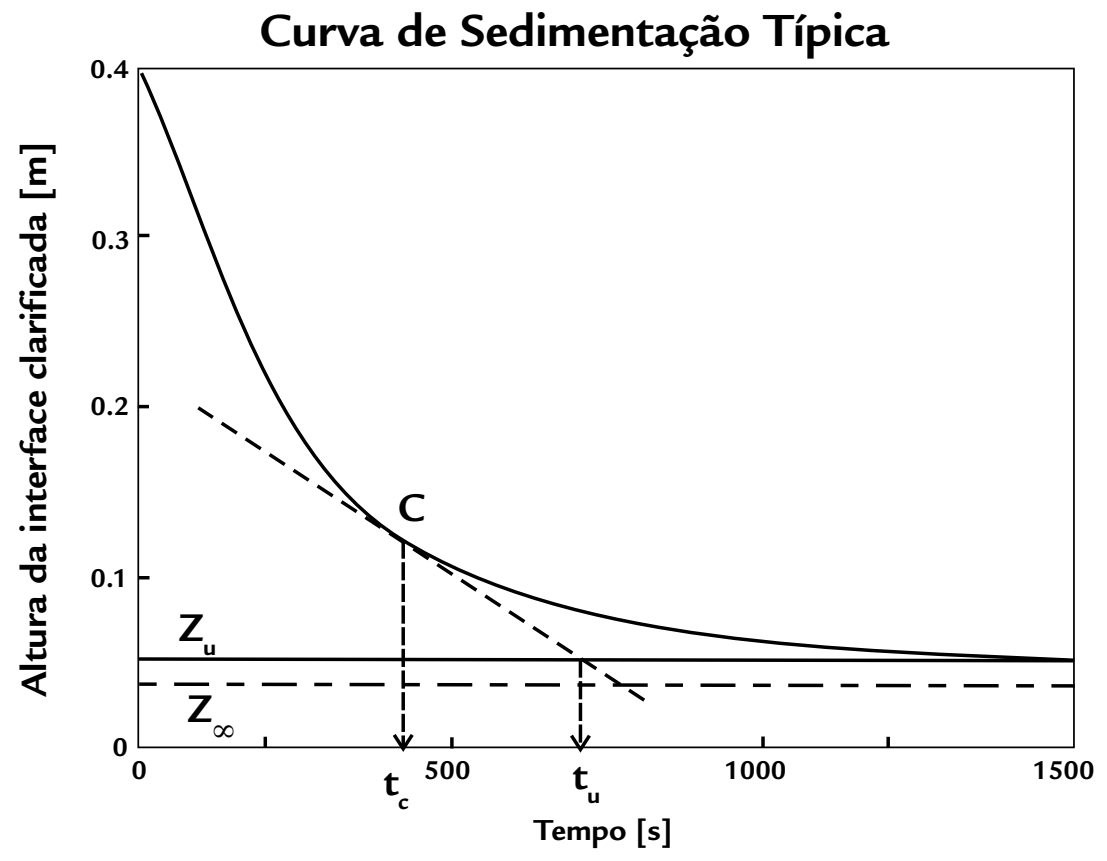

Figura 1

Sedimentação de lama de minério de ferro, segundo o traçado de Talmage-Fitch clássico. Valores simulados para a lama de Fábrica, sob as seguintes condições: concentração mássica de sólidos na alimentação $c_{\text {ma }}=4,9 \%$; concentração mássica de sólidos no espessado: $\mathrm{c}_{\mathrm{mu}}=$ 30,0 \%; $\mathrm{pH} 7,2,15 \mathrm{~g} / \mathrm{t}$ de floculante Flonex 9026 e início de compressão em 420 s; parâmetros regressionais da Equação 1 iguais $a: a=1,591$ e $b=203$ s; coeficiente de correlação estatística de 99,3 \% ( $z_{u}$ refere-se à concentração do underflow e $\mathrm{z}_{\infty}$, àquela após $24 \mathrm{~h}$ ). 
unitária. A utilização de equipamentopiloto fica muito restrita também porque não é recomendado recircular os fluxos (underflow e overflow) na alimentação (o que poderia resultar a quebra de flocos e alteração na dosagem de reagente).

Em inúmeros autores (como, por exemplo: Laros e colaboradores, 2002; Osborne, 1981; Oliveira e colaboradores, 2004; Pinto e colaboradores, 2009; Simonsen e Almeida, 1991; Torquato, 2008), apresentam-se os mais utilizados métodos de dimensionamento, quais sejam: Coe e Clevenger; Kynch com traçado de Talmage e Fitch; Kynch com traçado de Oltmann; Wihelm-Naide.

$\mathrm{O}$ método mais utilizado tem sido o de Kynch-Talmage-Fitch. O tempo de sedimentação, tu, utilizado para dimensionamento da área unitária é determinado pela intersecção da tangente à curva de sedimentação no ponto de início de compressão, C, com a ordenada da linha horizontal, que representa a concentração dos sólidos no espessado, conforme apresentado no gráfico (Figura 1).

$\mathrm{Na}$ prática de dimensionamento adotada atualmente pela Vale, porém, o procedimento tem contrariado a des-

\begin{tabular}{|c|c|c|c|c|c|c|c|c|c|}
\hline \multicolumn{10}{|c|}{ Utilização dos espessadores nas instalações da Vale } \\
\hline \multirow{2}{*}{\multicolumn{2}{|c|}{ Mina }} & \multirow{2}{*}{ Qtd } & \multirow{2}{*}{ Aplicação } & \multicolumn{2}{|c|}{ Alimentação } & \multirow{2}{*}{$\begin{array}{c}\left.c_{\text {ma }}{ }^{*}\right) \\
\%\end{array}$} & \multirow{2}{*}{$\begin{array}{c}\left.c_{\mathrm{mu}}{ }^{(* *}\right) \\
\%\end{array}$} & \multirow{2}{*}{$\begin{array}{c}\text { Área unitária } \\
\mathrm{m}^{2} / \mathrm{t} / \mathrm{dia}\end{array}$} & \multirow{2}{*}{\begin{tabular}{|c|} 
Diâmetro \\
$\mathbf{m}$
\end{tabular}} \\
\hline & & & & t/h & $d_{50}(\mathrm{~mm})$ & & & & \\
\hline \multirow{2}{*}{\multicolumn{2}{|c|}{ Cauê }} & 2 & lama & 143 & 0.0061 & 3.5 & 40 & 1.220 & 73 \\
\hline & & 2 & pellet feed & 55 & 0.0550 & 15 & 60 & 0.535 & 30 \\
\hline \multirow{2}{*}{\multicolumn{2}{|c|}{ Conceição }} & 1 & lama & 190 & 0.0064 & 4.2 & 35 & 1.722 & 100 \\
\hline & & 2 & pellet feed & 600 & 0.0520 & 45 & 65 & 0.049 & 30 \\
\hline \multicolumn{2}{|c|}{ Água Limpa } & 1 & lama & 42 & 0.0048 & 2.3 & 25 & 0.344 & 21 \\
\hline \multirow{2}{*}{\multicolumn{2}{|c|}{ Brucutu }} & 1 & lama & 250 & 0.0043 & 0.93 & 25 & 1.309 & 100 \\
\hline & & 2 & pellet feed & 1100 & 0.0670 & 47 & 65 & 0.034 & 34 \\
\hline \multirow{2}{*}{\multicolumn{2}{|c|}{ Gongo Soco }} & 1 & lama & 100 & 0.0067 & 6 & 40 & 0.131 & 20 \\
\hline & & 1 & pellet feed & 120 & 0.0610 & 47 & 65 & 0.027 & 10 \\
\hline \multirow{4}{*}{\multicolumn{2}{|c|}{ Alegria }} & 1 & alim. fotação & 500 & 0.0440 & 52 & 60 & 0.008 & 11 \\
\hline & & 2 & pellet feed & 370 & 0.0490 & 43 & 65 & 0.011 & 11 \\
\hline & & 1 & lama & 59 & 0.0045 & 3.2 & 35 & 0.987 & 42 \\
\hline & & 1 & lama & 57 & 0.0048 & 3.2 & 35 & 0.521 & 30 \\
\hline \multirow{2}{*}{\multicolumn{2}{|c|}{ Fábrica Nova }} & 1 & lama & 220 & 0.0056 & 5.1 & 45 & 0.553 & 61 \\
\hline & & 1 & pellet feed & 800 & 0.0450 & 48 & 65 & 0.037 & 30 \\
\hline \multicolumn{2}{|c|}{ Timbopeba } & 1 & pellet feed & 520 & 0.0510 & 45 & 65 & 0.016 & 16 \\
\hline \multirow{2}{*}{\multicolumn{2}{|c|}{ Fábrica }} & 2 & lama & 180 & 0.0039 & 4.5 & 48 & 0.654 & 60 \\
\hline & & 1 & pellet feed & 560 & 0.0390 & 40 & 70 & 0.053 & 30 \\
\hline \multirow{6}{*}{$\stackrel{0}{0}$} & Usinas: & \multirow{2}{*}{1} & \multirow{2}{*}{ lama } & \multirow{2}{*}{230} & \multirow{2}{*}{0.0044} & \multirow{2}{*}{3} & \multirow{2}{*}{30} & \multirow{2}{*}{0.288} & \multirow{2}{*}{45} \\
\hline & ITMA, B e D & & & & & & & & \\
\hline & ITMA e B & 1 & pellet feed & 192 & 0.0460 & 50 & 70 & 0.029 & 13 \\
\hline & ITMD & 1 & pellet feed & 350 & 0.0460 & 50 & 70 & 0.115 & 35 \\
\hline & & 1 & lama & 180 & 0.0051 & 3.9 & 40 & 0.455 & 50 \\
\hline & ITMI & 1 & pellet feed & 670 & 0.0460 & 38.8 & 70 & 0.060 & 35 \\
\hline & Mutuca & 1 & lama & 340 & 0.0047 & & 55 & 0.060 & 25 \\
\hline & & 1 & \begin{tabular}{|l} 
alim. flotação \\
\end{tabular} & 550 & 0.0430 & 66 & 60 & 0.029 & 22 \\
\hline Var & rgem Grande & 1 & lama & 450 & 0.0067 & 2.5 & 55 & 0.147 & 45 \\
\hline & & 1 & pellet feed & 410 & 0.0480 & 42 & 70 & 0.039 & 22 \\
\hline & & 2 & lama & 750 & 0.0010 & 18 & 50 & 0.279 & 80 \\
\hline & Cravió & 1 & lama & 450 & 0.0010 & 18 & 50 & 0.182 & 50 \\
\hline & Carajás & 1 & lama & 75 & 0.0010 & 18 & 40 & 0.504 & 34 \\
\hline & & 2 & pellet feed & 295 & 0.0348 & 3 & 60 & 0.075 & 26 \\
\hline
\end{tabular}

(*) $c_{m a}$ - Concentração mássica de sólidos na alimentação.

$\left.{ }^{(* *}\right) c_{m u}$ - Concentração mássica de sólidos no underflow.

\section{Material e métodos}

\section{Dimensionamento dos espessadores}

Primeiramente, para determinação da área específica ou unitária, empreenderam-se ensaios convencionais em bancada de sedimentação em provetas, monitorando-se a evolução temporal da interface clarificada até o intervalo crição original, pois o tempo adotado é o referente à intersecção da tangente à curva de sedimentação no ponto $\mathrm{C}$ com a ordenada da linha horizontal, $\mathrm{z}_{\infty}$, que representa a concentração após $24 \mathrm{~h}$ de sedimentação (método aqui referido como Kynch-Talmage-Fitch modificado).

Desvio no dimensionamento resulta em superdimensionamento ou subdimensionamento da área de espessamento.

No que tange à prática operacional da Vale, os dados de processo praticados exitosamente estão sistematizados na Tabela 1.
Tabela 1

Espessadores no tratamento de minério de ferro da Vale. usual de 24 horas. A determinação do ponto de início de compressão foi feita usando-se o gráfico de Roberts, confor- 
me metodologia convencional.

Para permitir o escalonamento, realizou-se estudo, em escala industrial, durante 30 dias, utilizando espessador

\section{Determinação do custo de implantação de um espessador}

Para determinação desse custo, em função do diâmetro, seguiu-se o modelo regressional preconizado por Parkinson e Mular (1972), atualizado posteriormente por Mular (2002), o qual consiste na

\section{Resultados e disussão}

Incluem-se, aqui, os estudos em escala industrial e em laboratório (proveta) com lamas e polpas de pellet feed de diver- adoção de equação de potência (custo $=\mathrm{aX}{ }^{\mathrm{b}}$ ), onde $\mathrm{X}$ é uma característica típica do equipamento e onde a variação temporal do parâmetro a expressa um componente inflacionário e a variação do

sas instalações de tratamento de minério de ferro, oriundo das seguintes minas da Vale: Capanema (a $18 \mathrm{~km}$ de Itabirito,

\section{Estudos com lamas das Minas de Capanema e Timbopeba}

As condições reinantes no ensaio industrial encontram-se sumarizadas na
Tabela 2.

Área unitária ou específica real, $A_{u r}=\frac{A}{Q_{s}}=\frac{706,86 \mathrm{~m}^{2}}{(14,278 \mathrm{~kg} / \mathrm{s})}=\frac{706,86 \mathrm{~m}^{2}}{(51,4 \mathrm{t} / \mathrm{h} \times 24 \mathrm{~h})}=49,51 \mathrm{~m}^{2} /(\mathrm{kg} / \mathrm{s})=0,573 \mathrm{~m}^{2} /(\mathrm{t} / \mathrm{dia})$

Durante o estudo em escala industrial, apresentado na Tabela 2, foram realizados vários ensaios em proveta, mostrados na Tabela 3. O resultado da área unitária de espessamento (ensaio 3, da Tabela 3), obtida em escala de bancada, pelo método Kynch (0,898), foi dividido pelo resultado da área

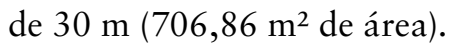

parâmetro exponencial b está ligada ao desenvolvimento tecnológico. Ressalte-se que os dados reais de aquisição da Vale nos últimos anos constituíram a nuvem de pontos experimentais.

MG); Timbopeba e Fábrica Nova (a 30 km de Mariana, MG); e Brucutu (a 9 km da Barão de Cocais, MG).

nesse caso:

unitária obtida em escala industrial $(0,573)$, resultando em um fator de correção de 0,64 .

Tabela 2

Resumo do estudo em escala industrial.

\section{Tabela 3}

Resultados de ensaios de

Obs.: O ensaio 3 representa bem a condição operacional (concentração de sólidos e dosagem de floculante). 


\section{Estudos com lamas das Minas de Fábrica Nova e Brucutu}

O fator de correção $(0,64)$ multiplicativo para o valor da área unitária, determinada pelo método de Kynch, Talmage e Fitch (modificado), foi utilizado para o dimensionamento dos espessadores de lamas dos circuitos de tratamento das minas de Fábrica Nova e de Brucutu (Figura 2). Note-se que o desempenho industrial desses equipamentos está compatível com o dos ensaios de sedimentação realizados em escala de bancada (proveta), portanto, validando, assim, a aplicação da metodologia aqui preconizada.

A Figura 2 apresenta um gráfico comparativo dos métodos de dimensionamento, referentes aos ensaios de

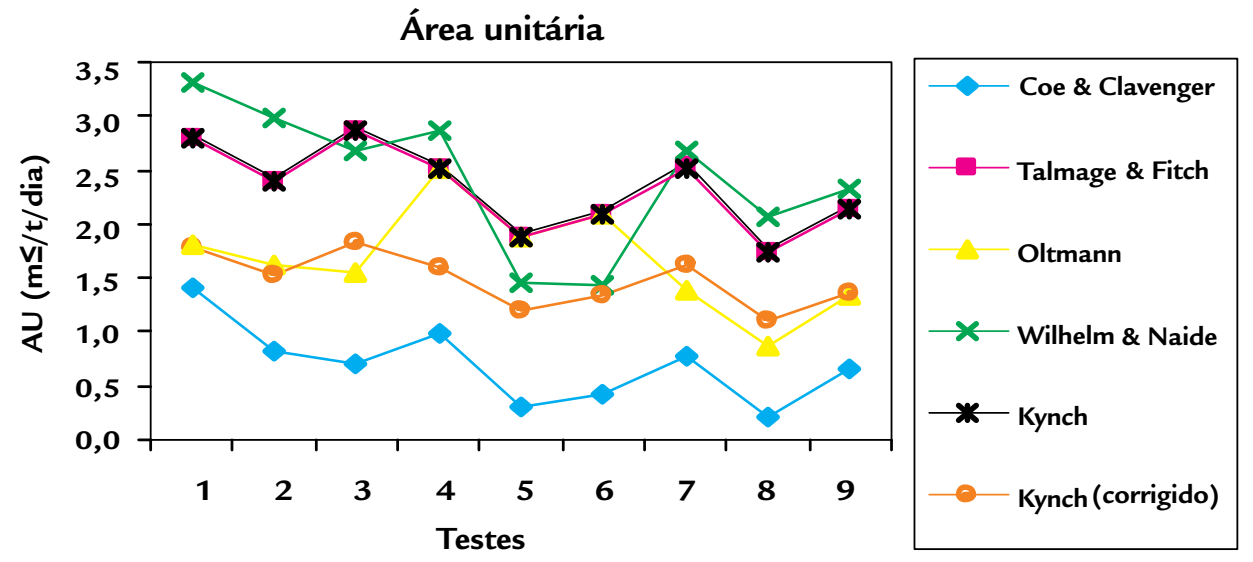

sedimentação com lama da mina de Brucutu (durante seu estágio inicial de desenvolvimento de processo), para os vários métodos de sedimentação. Nesse gráfico, pode ser observado que, à exceção dos métodos Kynch e de Talmage e Fitch, todos os demais "flutuam" em relação à curva "Kynch corrigido".

Figura 2

Gráfico comparativo dos métodos de dimensionamento, referentes aos ensaios iniciais de sedimentação com lama da mina Brucutu.

\section{Dimensionamento de espessador de concentrado (Pellet Feed)}

O método foi o mesmo do estudo do espessamento de lamas. A granulação mais grossa e o maior teor de ferro resultaram em melhor visualização da interface. Como a flotação reversa de minério de ferro se dá em $\mathrm{pH}$ básico, a dispersão das lamas (cujos pontos isoelétricos caem na faixa ácida) ocasionou aumento da turbidez do clarificado.

A turbidez, normalmente, não causa dano e, nesse caso, a dosagem de floculante não deve ultrapassar a $7 \mathrm{~g} / \mathrm{t}$, para se evitar torque elevado no sistema de raspadores, bem como não se prejudicar a filtragem subsequente por colmatação do meio filtrante.

Em alguns circuitos (Timbopeba, Alegria e Fábrica Nova), os espessadores de pellet feed operaram, durante certo período, na capacidade máxima e os ensaios em proveta mostraram compatibilidade

\section{Custo de implantação de espessadores}

O custo de implantação de espessadores convencionais de lama e de concentrado de minério de ferro na prática brasileira está ilustrado na Figura 3. No caso utilizou-se o diâmetro como característica de escalonamento $(\phi)$ do

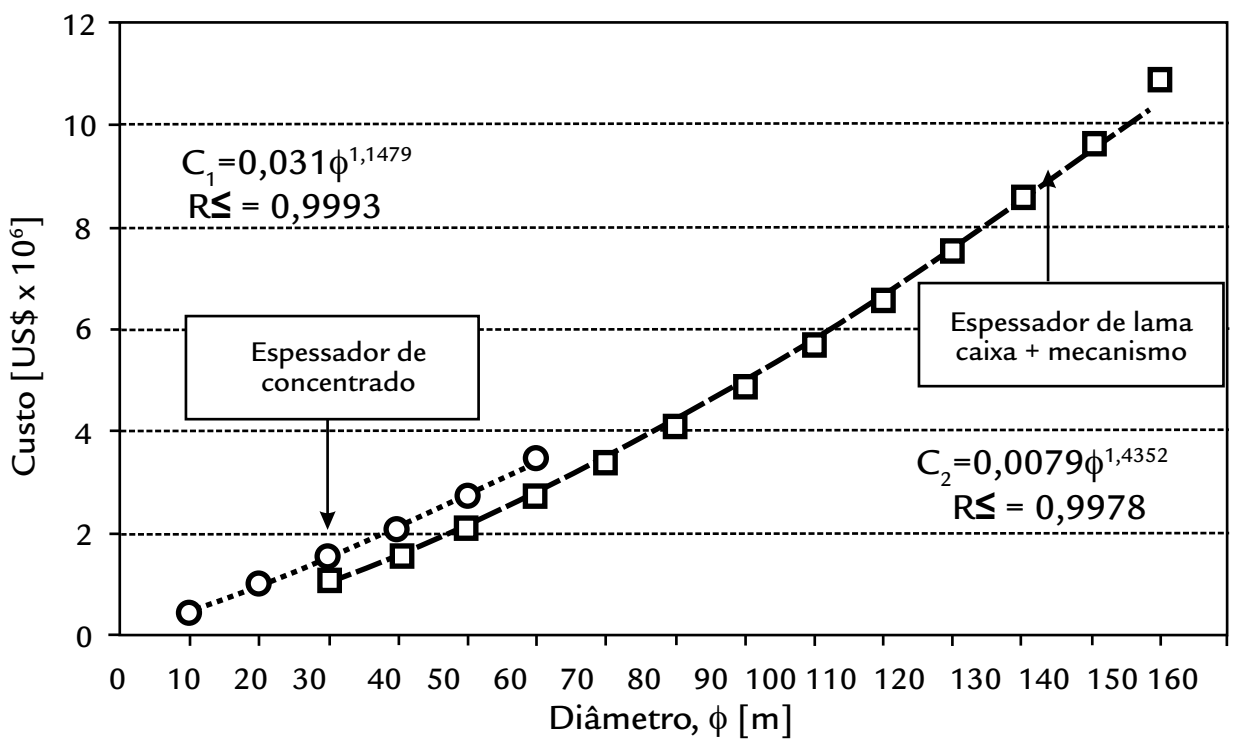

com o dimensionamento. No entanto, foi aplicado o fator de correção, multiplicativo, de 1,3. Esse fator, também, foi defendido por Simonsen e colaboradores (1991), principalmente para os concentrados de flotação, pois, a espuma remanescente perturba o processo de sedimentação, requerendo maior área unitária. Os resultados de Pinto e colaboradores (2009) também apontam nessa direção.

custo $(C)$.

$\mathrm{Na}$ Figura 3, $\mathrm{C}_{1}$ e $\mathrm{C}_{2}$ são custos para espessador de concentrado e de

Figura 3

Investimento de espessadores convencionais. 
lama, respectivamente, a partir de banco de dados da Vale (Torquato, 2008).O

\section{Conclusão}

Para se evitar o superdimensionamento dos espessadores, aplicados no espessamento de lamas de minério de ferro, utilizando-se a metodologia da Vale, a área unitária de espessamento calculada deve ser multiplicada por 0,64. Para não acarretar subdimensionamento dos espesssadores de expoente obtido por Parkinson e Mular (1972), para o conjunto bacia (caixa) e

mecanismo de raspagem, foi $b=1,38$.

pellet feed, multiplica-se por 1,3 o resultado da área unitária de espessamento, obtida através do método de Kynch-Talmage-Fitch modificado (Vale). A metodologia aqui preconizada mostrou respaldo em escala industrial, nos circuitos de tratamento das minas de Capanema, Fábrica Nova e Brucutu, e vem sendo aplicada nos demais projetos da Vale. A extrapolação das conclusões aqui exaradas para o beneficiamento de minérios não similares àqueles estudados (ou em caso de grande divergência de rotas de processo), entretanto, deve ser feita com extrema cautela.

\section{Referências bibliográficas}

LAROS, T. et alii. Testing, sizing, and specifying sedimentation equipment. In: MULAR, A. L. et alii. Mineral processing plant design, practice, and control: proceedings. Littleton: SME, 2002. v. 2, p.1295-1311.

LUZ, J. A. M. da. Fracionamento granulométrico de sistemas particulados. Ouro Preto: Departamento de Engenharia de Minas. Universidade Federal de Ouro Preto. 2009. p. 16-46.

LUZ, J. A. M. da. Aspectos reológicos de polpas em sedimentação. In: CONGRESSO DA ABM, 64. Belo Horizonte: ABM, 2009b.

MULAR, A. L. Major processing equipment costs and preliminary cost estimations. In: MULAR, A. L. et alii. Mineral processing plant design, practice, and control: proceedings. Littleton: SME, 2002. v. 2, p. 310-325.

OLIVEIRA, L.M., LUZ, J. A. M., LACERDA, C. M. M. Apostila de espessamento e filtragem. Ouro Preto: Departamento de Engenharia de Minas. Universidade Federal de Ouro Preto. 2004. p. 16-46.

OSBORNE, D. G. Gravity Thickening. In: SVAROVSKY, L. (ed.). Solid-liquid separation. (2.ed.). 1981. p. 121-155.

PARKINSON, E. A., MULAR, A. L. Mineral processing equipment costs and preliminary capital cost estimations. Montreal: Canadian Institute of Mining and Metallurgy, $1972.141 \mathrm{p}$.

PINTO, T. C. de S. et alii. Dimensionamento de espessadores: validação experimental de três técnicas convencionais. Revista Escola de Minas, Ouro Preto, v. 62, n. 2, p. 243-249, April/ June 2009.

SIMONSEN, R. M., ALMEIDA, C. H. Análise comparativa de métodos de dimensionamento de espessadores e computarização do método Wilhelm \& Naide. In: Fundação Christiano Ottoni. 1991. p. 654-666. (Curso de Sedimentação).

TORQUATO, N. C. Dimensionamento de espessadores convencionais aplicados a polpas de minérios de ferro. Ouro Preto: UFOP, 2008. 125 p. (Dissertação de Mestrado).

Artigo recebido em 29 de dezembro de 2009. Aprovado em 27 de janeiro de 2010. 